\title{
Full Mouth Rehabilitation along with Bilateral Precision Attachments
}

\author{
Dinesh BNVK ${ }^{1}$, Sravanthi $\mathrm{G}^{2}$, Sudhir $\mathrm{N}^{3}$, Taruna $\mathrm{M}^{4}$
}

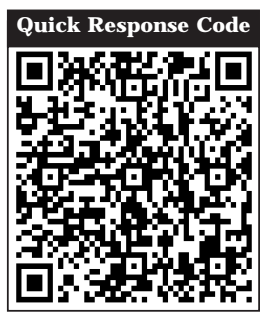

doi: 10.5866/2014.611495

1,2Post Graduate Student

3\&4Professor

Department of Pokrosthodontics

Kamineni Institute of Dental Sciences

India

\section{Article Info:}

Received: October 11, 2013

Review Completed: November 12, 2013

Accepted: December 12, 2013

Available Online: February, 2014 (www.nacd.in)

(C) NAD, 2014 - All rights reserved

\section{Email for correspondence:}

buragadda8@gmail.com

\begin{abstract}
:
Precision attachment partial dentures have been used successfully on natural tooth abutments since 1920. There is significant number of patients who could benefit from this treatment option, both short and long term. However, lack of proper knowledge, overwhelming number of attachments available in the market, multiple adjustments and repairs are making dentist reluctant to offer and provide attachmentretained RPD to their patients. The purpose of this article is to providean overview and a simplified approach to this treatment modality by a clinical case report.
\end{abstract}

Key words: Precision Attachments , Extracoronal Attachment, Cast Partial Denture.

\section{INTRODUCTION}

Esthetically and functionally successful prosthetic rehabilitation requires car eful attention and meticul ous treatment planning. Precision attachments offer considerable advantages in dentistry because of their flexibility. The use of precision attachments adds a new dimension to dental treatment and also broadens the referral base of a dental surgeon. ${ }^{1}$ Successful restoration of the dentition requires plenty of contemporary and conventional treatment techniques and planning and attachment retained partial dentures are one such kind of treatment modality in prosthodontics. ${ }^{2}$ Precision attachments could be extracoronal and intracoronal. Intracoronal describes an attachment within the confines of the cusps and normal proximal axial contour or within the normal contours of the crown of a tooth. ${ }^{3}$ Extracoronal is that attachment which exists outside, or external to, the crown portion of a natural tooth. The extracoronal attachment projects outside the crown and provides either a rigid or resilient connection between the teeth and the prosthesis. Attachment-retained cast partial dentures facilitate both esthetic and functional replacement of missing teeth. Studies have shown a survival rate of $83.35 \%$ for 5 years, of $67.3 \%$ up to 15 years, and of $50 \%$ when extrapolated to 20 years. ${ }^{4}$ This paper describes a case report of a patient with maxillary and mandibular bilateral distal extension Kennedy's 
class I modification 1 respectively, which is prosthetically restored using a extracoronal castable precision attachment (RHEIN 83 OT attachments system).

\section{Case report:}

A 54 year old femal e patient came to department of prosthodontics with the chief complaint of missing teeth in the upper and lower back region and few in the front region with difficulty in eating. Patient is totally depressed with her appearance and became nonsocial. .On intra oral examination the missing teeth were 14, 15, 16 17, 22, 23, 24, 26, 27, 31, 32, $35,36,37,41,46$ and 47 (Figure 1). There was generalized attrition of remaining teeth. Endodontic treatment was performed in relation to $11,12,13,21$, $33,34,42,43,44$ and 45 . On radiographic examination, based on the condition of the available alveolar bone and teeth, full mouth rehabilitation is done in the maxillary and mandibular region, with fixed partial denture and bilateral precision attachments.

\section{Technique:}

- Diagnostic impressions were madeand mounted on semi adjustable articulator using a face bow. In order to assess the lost vertical height. Patient was given an acrylic removable partial denture. Patient is recalled after two weeks to verify the increased vertical height. Patient got adjusted to the given vertical height without any symptoms. Diagnostic wax up is done on the mounted casts. A putty matrix (zeta plus csilicone, zermach.) was made over the completed diagnostic wax-up.

The attachment system was selected on the basis of available space. (OT CAP, Rheine 83 Inc, USA). Tooth preparation was done on 11, $15,21,22,23,32,33,34,35,43$ and 44 (Figure 2). I mpressions made and cast poured with die stone. Wax pattern made on all prepared teeth.

- The male component was attached to the axial surfaces of the abutments bilaterally on both the arches in relation to $15,23,35$ and 44 using a dental surveyor, investing and casting was done. Metal try-in of the copings was done to evaluate the fit of the casting. Ceramic layering was done on the metal frame work and tried (Figure 3). The fabricated metal ceramic crowns were provisionally cemented with the attached male components and pick up impression is madeusing putty, light body (Aquasil, Densl py) to fabricate the removable partial denture with bilateral precision attachments.

- Casts were poured from the impression and removable frame work is fabricated over the cast with female component. The removable framework is tried in the patients mouth with the incorporated female component (housing and nylon cap) evaluated for passive fit over the o-ring (male component). Occlusal rims were fabricated on the framework of the maxillary and mandibular removable partial denture, maxillomandibular relations were recorded. Teeth arrangement and try in was done foll owed by Acrylization (Figure 4). The fixed partial denture was cemented with glass ionomer cement and the removable partial denture with bilateral precision attachment is inserted (Figure 5). Post insertion checkup was done for 1 to 2 week interval.

\section{DISSCUSSION:}

Dr. Herman Chayes first reported the invention of attachment in early 20th century. To the late 20th century, with growing technology the attachment has been applied to the superstructure of implant ${ }^{5}$. Precision attachment has exceptional feature of being a removable prosthesis with improved aesthetics, less post-operative adjustments and better patient comfort and psychology are drastically improved. ${ }^{6}$ They are mostly indicated in long edentulous spans, distal extension bases and non parallel abutments.

Stress control on the abutment is an essential factor for the success of distal extension cast partial denture which is achieved through dual impression technique, broad coverage, stable denture base , rigid design, physiologic shimming, splinting of abutments, proper selection of attachments. ${ }^{7-8}$

The recommended procedure has several advantages over the conventional prosthesis. In this case report abutments were of adequate clinical crown height to receive attachment; multiple abutments were spl inted anterior to edentul ous span to aid in better distribution of stresses. As the cast partial denture is a fixed removable type, maintenance of the oral hygiene is relatively easy. Added to this the laboratory procedures are simple due to the available preformed prosthetic components and the treatment is economical. By the end of the treatment patient comfort and psychology had drastically improved and started participating in social activities. 


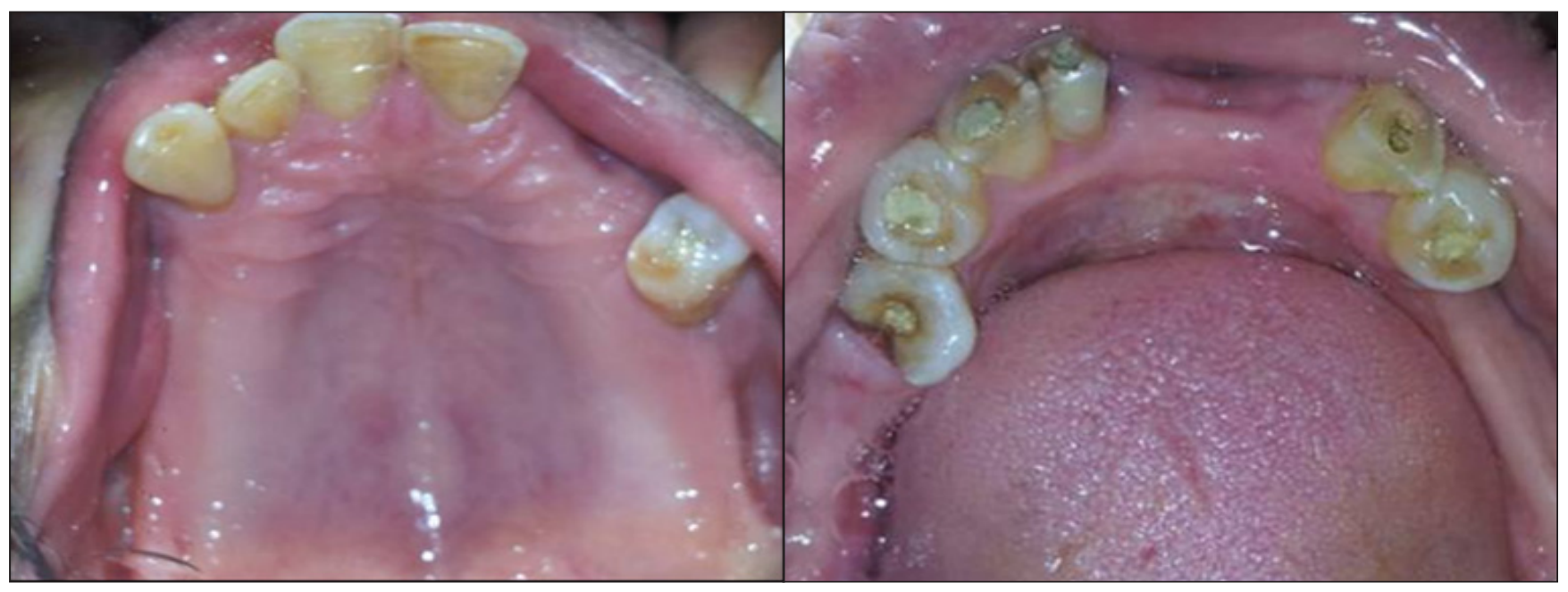

Figure 1: Preoperative intra oral view

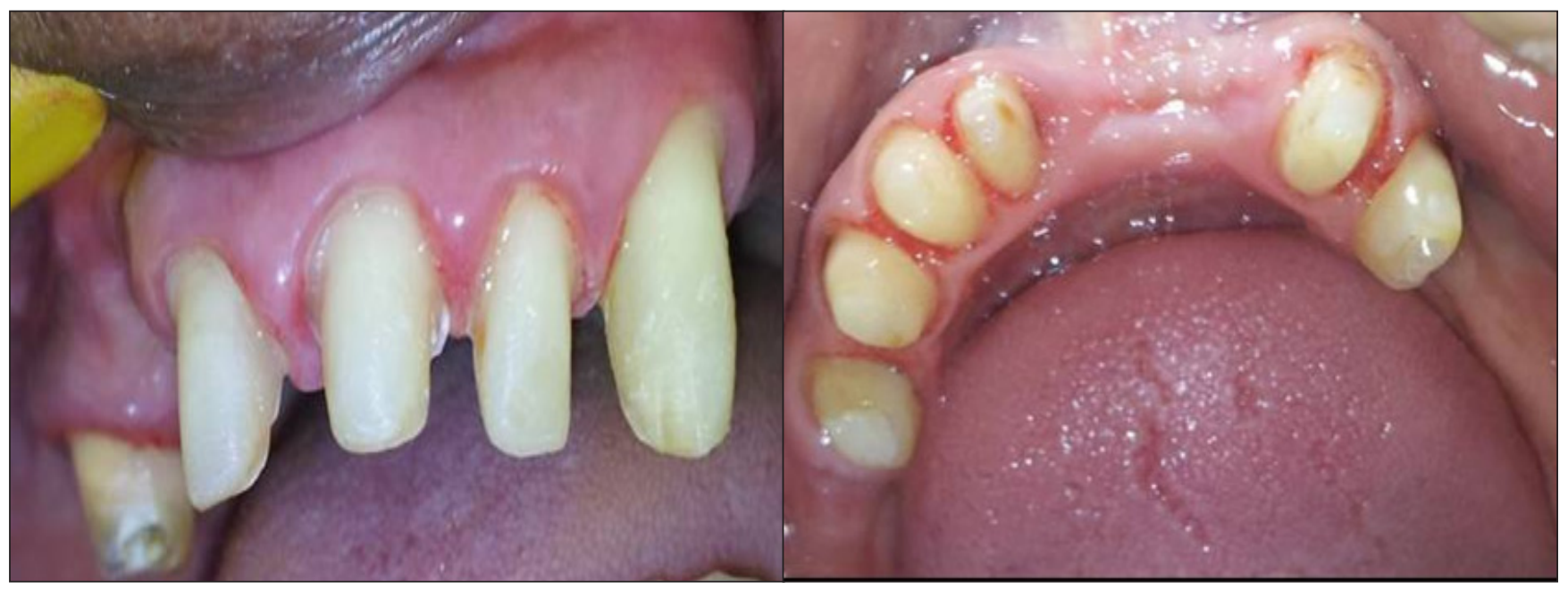

Figure 2: Tooth preparation

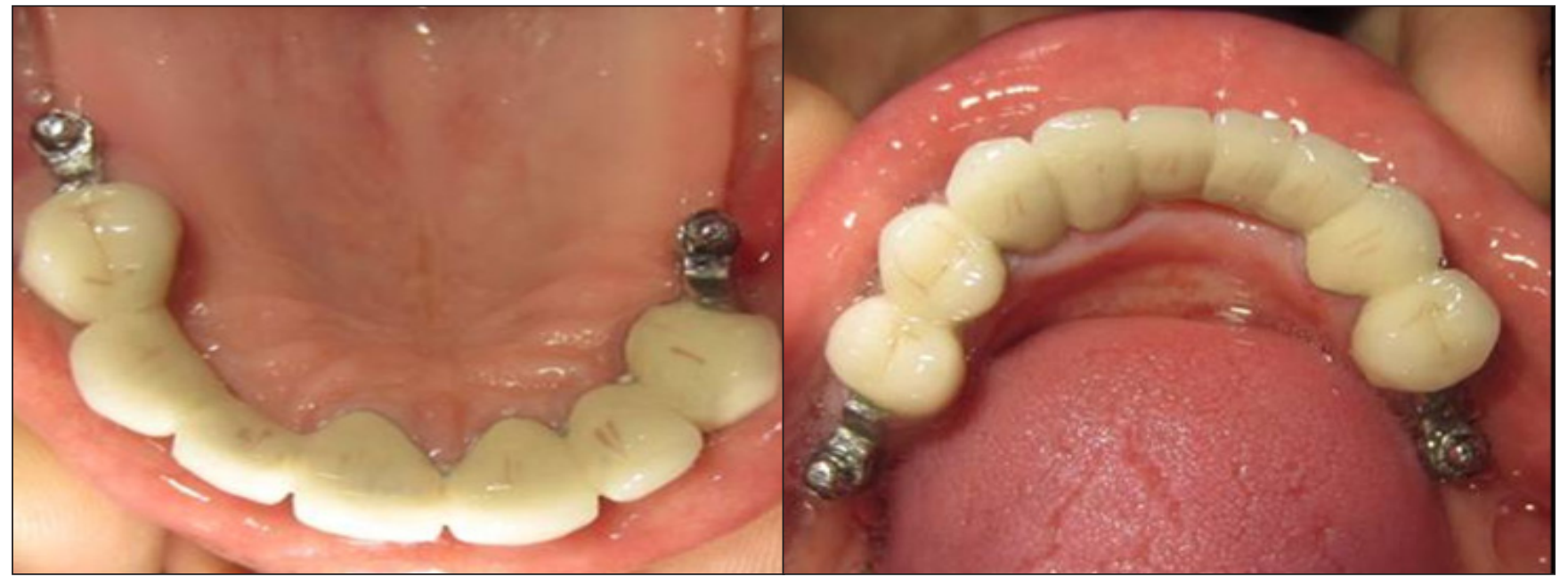

Figure 3: Try in of the porcelain fused metal prosthesis. 


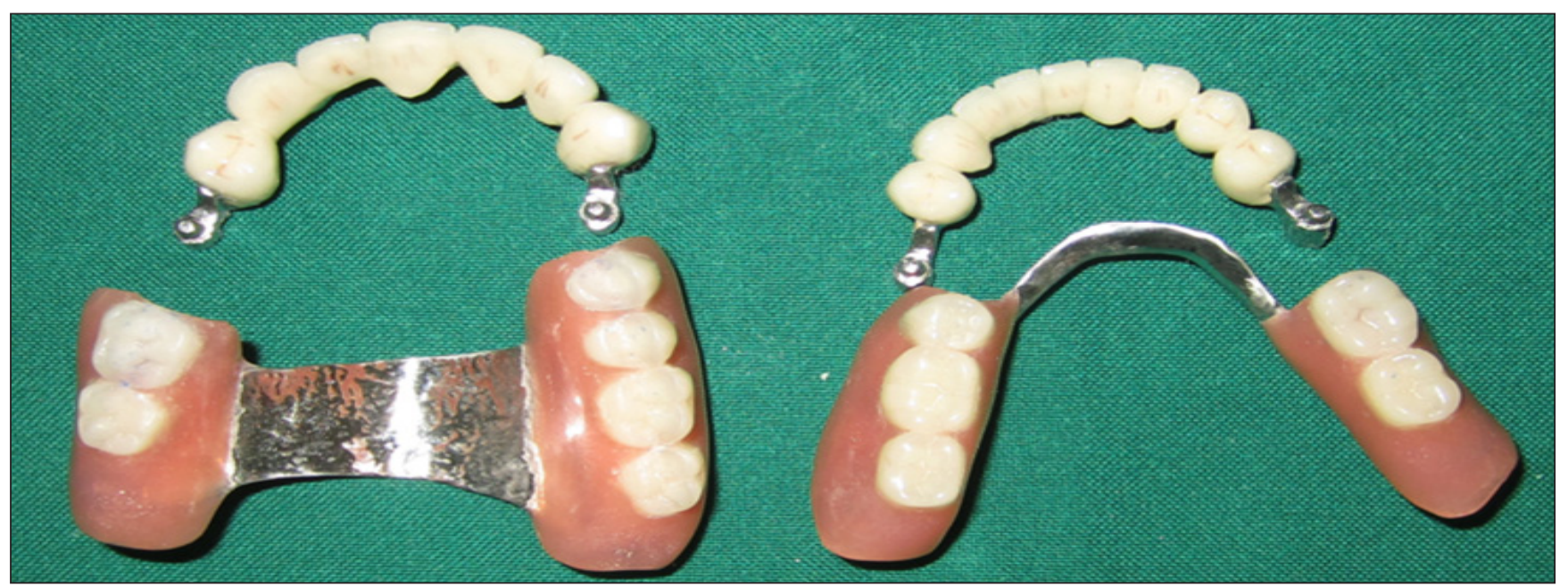

Figure 4: Completed frame work.

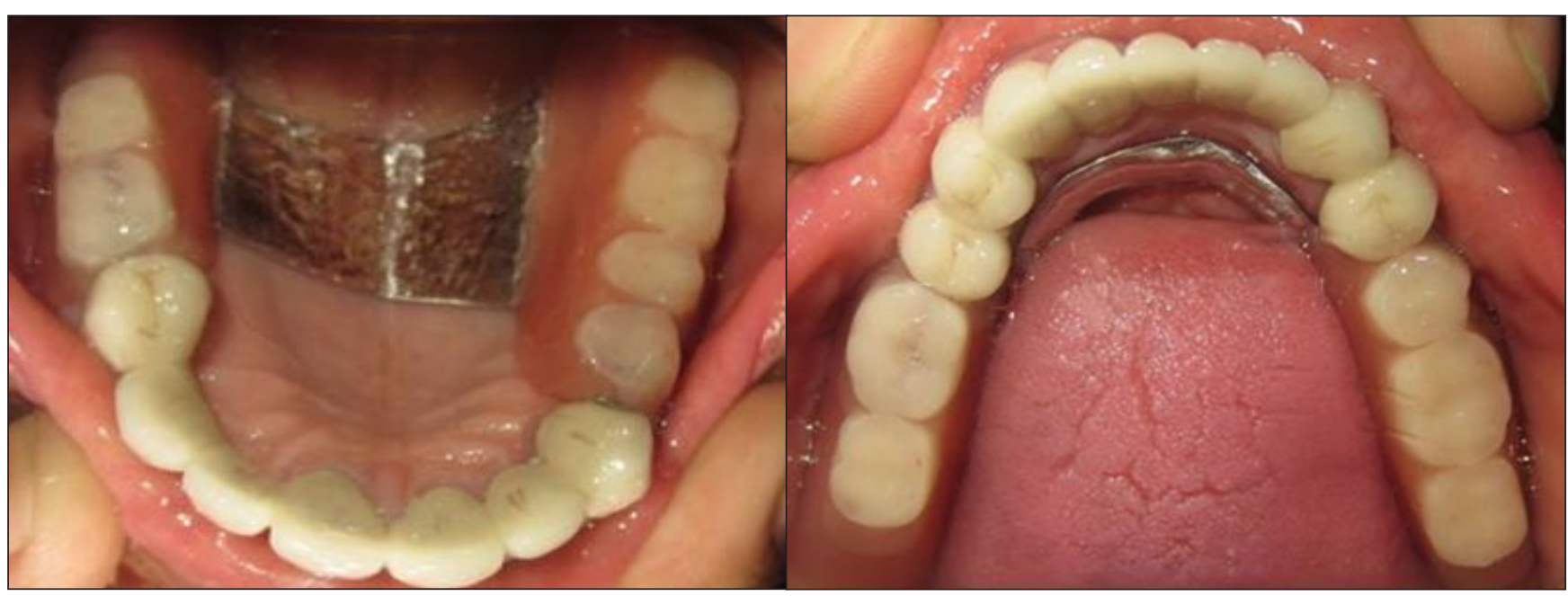

Figure 5: Postoperative intraoral view.

\section{Conclusion:}

A comprehensive evaluation, multi-disciplinary approach and a sequential treatment plan, worked out in harmony with the patient's aesthetic demand , perceptions, and periodic recall preventative therapy is important for a long-term successful outcome of fixed removable precision attachment retained removable partial denture.

\section{REFERENCES:}

1) Anupama Nigam, Ajay Singh, Et Al Precision AttachmentsAn Overview. J Dento facial Sci 2013; 2(4): 41-44.

2) Nitin Bhaskar Shetty, Sanyuktha Shetty Et Al Precision Attachments for Aesthetics and Function: A Case Report .J Clin Diagn Res 2014; 8(1): 268-270.

3) Elliot Feinberg, Edward M. Feinberg Et Al .Attachment Retained Partial Denture. Nys Dent J 1984:161-164.
4) Summit Makkar, Anuj Chhabra, Et Al Attachment Retained Removable Partial Denture: A Case Report. Int. J Clin Dent Sci 2011; 2(2) 39-43.

5) Preiskel Hw. Precision Attachments In Prosthodontics: Over dentures And Telescopic Prostheses. Volume 2. Chicago, Ii: Quintessence Publishing Co, Ltd; 1985.

6) Feinberg E. Diagnosing and Prescribing Therapeutic Attachment-Retained Partial Dentures. Nys Dent J .1982; 48 (1):27-29.

7) Preiskel H. Precision Attachments for Free-End Saddle Prostheses. Br Dent J 1969; 127:462-468.

8) Picton Dc, Willis Dj. Viscoelastic Properties of The Periodontal Membrane and Mucous Membrane. J Prosthet Dent 1978; 40:263-272.

9) Burns Dr, Ward J e. A Review of Attachments for Removable Partial Denture Design: Part 1. Classification and Selection. Int J Prosthodont 1990; 3:98-102. 